\title{
A Conceptual Study on E-marketing and Its Operation on Firm's Promotion and Understanding Customer's Response
}

\author{
Goodarz Javadian Dehkordi ${ }^{1}$, Samin Rezvani ${ }^{1}$, Muhammad Sabbir Rahman ${ }^{1}$, Firoozeh Fouladivanda ${ }^{1}$ \\ Neda Nahid ${ }^{1} \&$ Samaneh Faramarzi Jouya ${ }^{2}$ \\ ${ }^{1}$ Graduate School of Management, Multimedia University, Cyberjaya, Malaysia \\ ${ }^{2}$ Faculty of Business Management and Globalization, Limkokwing University, Cyberjaya, Malaysia \\ Correspondence: Goodarz Javadian Dehkordi, Graduate School of Management, Multimedia University, \\ Cyberjaya, Malaysia. Tel: 60-173-410-681. E-mail: goodarzone@gmail.com
}

\author{
Received: May 22, 2012 Accepted: September 10, 2012 Online Published: October 1, 2012 \\ doi:10.5539/ijbm.v7n19p114 URL: http://dx.doi.org/10.5539/ijbm.v7n19p114
}

\begin{abstract}
The purpose of this conceptual paper is to discuss four main different tools which are: mobile marketing, E-mail marketing, web marketing and marketing through social networking sites, which use to distribute e-marketing promotion and understanding their different influence on consumers ' perception. This study also highlighted the E-marketing, marketing through internet, mobile marketing, web marketing and role of social networks and their component in term of perceptual differences and features which are important to them according to the literatures. The review of the research contains some aspect of mobile marketing, terms like adaption, role of trust, and customers' satisfaction. Moreover some attributes of marketing through E-mail like Permission issue in Email in aim of using for marketing activity and key success factor base on previous literatures.
\end{abstract}

Keywords: E-marketing, internet marketing, mobile marketing, E-mail marketing, web marketing

\section{Introduction}

As we move into the twenty-first century, the way that firms and companies do business has changed, furthermore, it is readily apparent that such changes are attributable to the advent of the Internet (Ainin and Noor Ismawati 2003). The economy of the world nowadays is transitioning from an economy that is just related to goods to an economy in which value creation, employment and economic wealth is very important. An overview of the Internet shows that this phenomenon is not only a networking media but also a place for consumers to conduct their transactions on the global market. The speed of innovation increases day-by-day, and this era has the highest rate in the speed of the enhancement of technology in comparison with any previous era. Undoubtedly, usage of the Internet and computer has an important influence on this issue. Nowadays, we can easily see that for many people use of the Internet and computer devices, smart phones as well as emails and even logging on to social media sites like Face book, LinkedIn or twitter has become an essential daily need (Raad, Yeassen et al. 2010).

In global view, Electronic Marketing (E-marketing) mostly defines as new attitude and modern realistic involvement with marketing of goods, services, information and even ideas via internet and other electronic means (El-Gohary 2010). By reviewing literatures about this subject one of the main impediments is unclear definition from the researcher and authors about E-marketing, -commerce, E-business and internet marketing, Most of the researcher misused the meaning of these four and may use E-marketing E-commerce, E-business, and internet marketing as equal meaning with different wording which is not correct. E-marketing has broader scope while internet marketing just refers to internet thing like world wide web (www) and electronic mail, while E-marketing include all above plus tools like mobile phones, intranet and extranet and etc. On the other hand E-business and E-commerce have even broader scope in compare of E-marketing. E-marketing strategies involve existing utilities and combine them with communications and also data network to create a relationship with the firm and it customers by the communication happen in internet environment. E-marketing provides so many opportunities for the firms. One article briefly mentioned similarity modern era with agriculture era and declared: In agriculture era people tend to buy their needs from the stores which were close to them as recently even in developing countries people tend to do so .In this structure marketing transactions were related to customer and their initial adapted needs, this system shifted from this structure especially after world war II to 
modern marketing which is much more organized and product especially initiated ones first manufactured and then marketed by the marketers. To make story short E-marketing is very similar to marketing in agriculture era but with much more decreases in cost (Sheth and Sharma 2005). E-marketing involves using information technology which applied to traditional marketing practice. E-marketing tries to hasten the marketing efficiency and its effectiveness in way of traditional marketing was undeveloped in them. Consequently, electronic marketing and all its strategies added customer value further than what traditional marketing could gain. E-marketing in point of view of e-business begun to enhance and reinvent the mean of traditional business beside internet played vital role in this process. Marketing through electronic devices lied at the main part of integrating information technology and marketing attributes. Add value to products, increase quality of services create facilitate relationship between firms and customers and have better concept about the market place and etc are all options that have been offered by this almost new phenomenon of doing business (Tehrani, Majid nik 2008).

\section{Internet Marketing}

From April 1995 to ending April 2000, was known as dot.com boom. During this 5 year period hundreds of businesses tend to use internet as a primary means of doing their transaction with their consumers and declare themselves in public offering, Consequently many of the firms terminated their operation and many others try to exist with adequate business change. This subject focused by so many researchers as considerable attention issue in business world and obviously creates scholarly activity as well as other research. Meanwhile e-tailers develop and introduce new internet base marketing aspect and as a result new world for marketing. Internet marketing as a part of e-marketing developed about websites for business to robust and rescale their traffic, advertisement industry , auction oriented site like eBay have been grown through word of mouth, beside customer relation management (CRM) also gets better situation and its emphasizes gets more on personalization much more easy than before, unless the unite concept of E-marketing has not appeared (Kalyanam and McIntyre 2002).The potential of using internet has been documented so many times in so many journals and also in so many researches. On the other hand both successful and unsuccessful marketing through internet has been published too; moreover there is no specific method and rout for manager that prove for them obeying that particular way will bring for them successful business by internet unless they put large investment and take the risks in this way in case of facing to their current channels of distributing their market. One of the major issues in this subject is product characteristic which plays important role in marketing through internet and the way to promote this product to the consumer. Internet marketing in recent decade has very huge movement forward, many companies all over the world mainly use internet for advertisement or corporate promoting activity beside not many companies fully utilize their system with recruiting the power of internet in business as new channel of doing transactions.(Kiang, Raghu et al. 2000).

Reviewing literature about E-commerce shows advantages of internet as a platform to sell the product which can be classified into three major functions:

- As a channel for communicating

- As a channel for doing the transactions

- As a channel for distributing

Moreover; ability of serving transaction and physical distribution can be notice as a unique ability that firms can find in this phenomenon (Kiang, Raghu et al. 2000).

Marketing over the internet create a basic changes not only in business but also in customers' behavior. Marketing provide a unique platform for the firms to understand the need of the customers and make the customers free from the time and place. It also reduces cost by omitting unnecessary transaction cost. (Sheth and Sharma 2005).

Integrating competitive strategies and internet is progressively becoming crucial factor for firms only in physical market place but also in electronic environment. Recruiting internet in this competitive environment creates some changes that illustrated in below:

Changes on development of relative emphasis on traditional channel:

- Providing a lot of information for the customers about any product

- Create communication between firms and customers

- Create customer promoting awareness

- Create facilities in doing transactions 
- Helping in distributing product and service

- Digitalizing product

Direct marketing, Strategic association and Leading marketing are three main parameters which have greater changes in marketing development.

Development in leverage of:

- Innovation

- Customization

- expansion

Development of potential that internet contains to follow new business model and strategies which firm may apply on their business to compete in competitive environment (Varadarajan and Yadav 2002). Below four tools which are mostly use for electronic marketing describe in detail and discuss about their componends:

\section{Mobile Marketing}

Mobile phone nowadays have become a product that every generation and mostly in any age people have on the other word this product became one of a handful of customers production and have majority of global acceptance in short period of time. Mobile phone became a central utility that customers need in their lives and youth and teen agers are not exception. In this among the widespread of adaption on this device create significant opportunities for marketer to use and increase their awareness and build connection between them and customers. This ability makes mobile as huge marketing tool for firms to serve and reach to customers anytime and anywhere (Persaud and Azhar 2012). Mobile marketing have become a two way or multi way communication device for the firms to build connection with their customers. Beside in such surge of usage of mobile devices in these days and the speedy growth of mobile application in market, the set of using this device to increase market profit and increase core competency for the firms has been become initiative way for both marketers and also firms which want to use this device in their marketing attributes(Shankar and Balasubramanian 2009).

Barnes and Scornavacca (2004), noted this issue that majority of research and most of the marketing techniques that in term of mobile marketing would be use to reach to customer are SMS base marketing or use push base practice, on the other hand technology of smart phones can open a wide range of marketing aspect for marketers to use it in beneficial way. E-wallet and RFID integrated to smart phones and marketers can use huge marketing innovation by considering this integration which was not available in classic type of mobile phones. There are so many applications like Amazon price check list or many similar applications that can enhance quality of delivering information to customer and also rise up customers' awareness (Barnes and Scornavacca 2004). Base on Persaud, A., and Azhar, I. (2012), talking and text massaging were initial capabilities that have been offered by classic phone but nowadays using smart phones like iphone or Blackberry with wide and high resolution screen contains various abilities like web browsing, so many applications, games and so on and marketers can use all this advantages in term of marketing aspect by offer data and encouraging them to use their smart phones in various way and more often (Persaud and Azhar 2012).

\subsection{Value of Customers in Mobile Context}

Value of customer in every business is a vital factor beside businesses always seeks ultimately to understand needs and want of their consumers better. Mobile medium base on its ability provides value in consumers' perceptions. Issues like "always be with the customers" or "always on device" are subject that investigate relationship in perceiving value and precursor in mobile context (Varnali and Toker 2010). Other literature mentioned mobile service formerly use for convenience and usefulness is not the main concern (Kim, Chan et al. 2007).More over its found that influence of fun aspect of mobile is much more stronger than utility attribute of this device. This subject is much more visible among mobile users who have lower internet experience and lower trust of mobile technology (Bauer, Barnes et al. 2005).

\subsection{Mobile Marketing Attitude}

Although adoption determinant the attitudes toward mobile advertisement and promotions which declared by them but several examples and articles demonstrate the strength aspect of mobile in entertainment and delivering information value (Bauer, Barnes et al. 2005). Haghirian and Inoue (2007) investigated in Japanese consumers' attitude towards advertisement in mobile device and found out credibility of information have the greatest impact in Japanese attitude (Haghirian and Inoue 2007). Another literature demonstrate strong relationship between consumer intentions and their attitudes in term of using mobile in business (Okazaki 
2004).Chowdhury and Pavin. 2006 found that price-conscious and involving customers in this subject have positive attitudes toward mobile advertisement, coupon that contains discount and even banking activities and mobile banking tools, also respondent among consumers without fixed line internet access differ from those who have in term of attitudes toward mobile ads, shopping and leisure activities (Chowdhury, Parvin et al. 2006).

\subsection{Adoption and Acceptance}

Articles which can be classified under this category generally focus on mobile marketing acceptance determinant. These articles mostly argued about acceptance of mobile marketing massage in dependant of some factors like customers' predisposition, inclinations, individual perception and attitudes(Varnali and Toker 2010).Moreover some articles discuss about demographic factor in accepting Mobile marketing massage (Bigné, Ruiz et al. 2007);(Hanley, Becker et al. 2006);(Suoranta and Mattila 2004). Beside factors like social influence(Kim and Zhang 2010); and cultural dimension (Gressgard and Stensaker 2006);(Sultan and Rohm 2008) plays important role in this aim. Research level about this subject is plentiful and issues related to demographic and gender differences, among most of them are controversial subject (Varnali and Toker 2010). According to Harvey Tanakinjal et al (2010), television was the first screen that people used to get information which has been provided for consumers by marketers, after that internet became another screen to fulfill this need. E-commerce brought another screen which calls the third screen for getting information in tem of increasing information and awareness of the customers which is Mobile marketing. Mobile medium as new marketing channel that mostly in literatures known as m-marketing creates a mean for companies to expand their market share with using this device. Target massage also is another capability of mobile marketing to target more effectively in compare of present mass media. Marketers notice mobile marketing as a way of doing marketing as potential way which help them to communicate with customers in appropriate manner (Harvey Tanakinjal, Deans et al. 2010)

\subsection{Role of Trust in Mobile Marketing}

Despite the incomparable abilities of mobile service and facilities that it has provided for business world, trust issue is a major complication in mobile loyalty and service development. Researched shows that many customers are not feel comfortable with the massages and idea with declared by mobile or wireless device (Varnali and Toker 2010). Karjaluato, Lehto in 2008 mentioned positive impact of trust in relationship of attitudes toward mobile advertisement and intention of massages which receive to customers (Karjaluoto, Lehto et al. 2008).

Zhang and Mao (2008) mentioned two finding about consequence of trust in mobile massages that send to customers:

- Recognizing ease of use and psychological disposition have significant influence in trust for advertisement which declared by mobile device.

- Trust increases behavioral intention in accepting SMS ads directly and indirectly in order of increase usefulness of massages which contains advertisement (Zhang and Mao 2008).

\subsection{Mobile Marketing and Satisfaction}

According to Kaan vernali and Toker, in compare of adaption and acceptance of mobile service context, satisfaction and loyalty not often been studied (Varnali and Toker 2010).Recent recent research shows relationship between value perception among customers and multimedia service which has been added to mobile service. Commitment to use same provider directly creates influence on commitment among customers; on the other hand emotional and value which perceived by MMS content indirectly enhance satisfaction and commitment. In addition quality of information which declared by mobile device (factors like quality of connection, context, interaction and content) have significant impact in customers' satisfaction (Chae et al 2002).

Surprisingly, design and aesthetic in mobile interface are focused lesser than other factors and few articles discuss about impact of beauty and design of the massage in mobile marketing (Varnali and Toker 2010). Conversely this factor in web sites has significant impact in E-commerce. Loyalty among internet user strongly depends on design and web content and this factor has important role in visiting particular website again and again by online customers. Studies over internet demonstrate that customers who are satisfied with the design would exhibit E-loyalty behavior in internet environment (Cyr, Head et al. 2006).Even though considering this issue that study about aesthetic, beauty and design in mobile content also level of research related to this issue is still inadequate and future studies will be valuable (Varnali and Toker 2010). 


\section{E-Mail Marketing}

Internet users send and receive a majority of emails daily or log to chat with their friends or with selected group of people with common interest over internet. People also use internet to web surfing or gathering information but the issue that all managers should know is that e-mail is the most usable media in the internet environment. Potential of e-mail in marketing aspect is not under veil and all the firms and companies always tries to prepare a list with their customer. e-mail as a source for preparing data and information both in customers mind and business owners was relatively attractive. Robert Hicks who is president of DM groups in a firm in Aurora have an idea about e-mail marketing and believes: "The ability to track information and define mailings is phenomenal. The ability to define potential consumers is fantastic. You deliver an e-mail message, in a couple of hours instead of a couple of weeks, at a CPM of $\$ 75$ per page and get a 5 percent response in 72 hours. The cheapest carrier route is about $\$ 145$, and the results aren't comparable". Some researchers explain about user group as a self selected group of people with common interest such as car, travel and so on. Researchers believes that user group in e-mail marketing is useful term to categorize base on community which they are interested in that provides for business to send email to right customer and satisfy that specific customer needs and wants (Jackson and DeCormier 1999).

E-mail marketing as the most cost effective tool in internet marketing has been mention in so many studies; in addition high rate of response from this tool has made this tools and tactic as interested criteria of so many studies and researches. In year $2000,61 \%$ of united state company use email as a tool in term of marketing tactic and estimated this amount gets higher day by day (Jackson and DeCormier 1999; Rettie 2002);(eMarketer 2000).Email marketing base on the definition is one kind of direct marketing tactic in term of using electronic devices to enhance the quality of service also increase customers attention and awareness which with no doubt brings more return for the firms and businesses in gaining profit. Email marketing can be considering as an electronic mails which deliver commercial massages to Email users and customers. This tactic is one the oldest and also one of the most effective tactics in E-marketing. Minimizing expenses with maximizing sale is unique fortune which can exist through this tool. Base on the finding of Salehi and Mirzaei, recruiting a good email marketing massage can be helpful in (Salehi, Mirzaei et al.):

- Rising sale communications and conversations between firms and customers, in that mostly customers would not do their purchase in the first web visiting.

- Create expense decreasing in repetition sales, means that firms by using e-mail can reduce their expenses in sale time and no need to pay again for customers 'notification.

- Introduce and create notification about new products and services for customers.

- Help the firms in achieving feedback from the customers easily.

- Push customers to do offline purchase

Mostafa Raad and Norizan Mohd Yeassen et al, 2010 in their paper describe e-mail marketing as one the best techniques for advertisement for online businesses. Majority of internet users especially e-mail user that day by day getting increase rapidly push the businesses to use this ability in their business and particularly in their marketing aspect and advertisement attributes. Those researcher explore E-mail marketing as a exclusive way for doing the marketing which is cheap to enroll and easy to access and as paramount dimension introduced that as the most effective way to gain return for firms by internet marketers (Raad, Yeassen et al. 2010) .

Many authors have discuss about E-mail marketing and its advantages, some authors describe that as a permitted relationship between marketers and customers to provide wealth communication (Jackson and DeCormier 1999) or other researcher define as a "internet's killer application" in that specific email can be modified, targeted and even track by the marketers (Wreden 1999).Peppers and Rodgers in year 2000 illustrated as invaluable tool in internet marketing that has high rate in response and also low cost in distribution and this two wonderful ability have made this tactic rapidly the most useful term in marketing through internet (Peppers and Rogers 2000) and some other believes that e-mail marketing can be useful in achievement or maintenance benefit for firms(Rettie 2002).In this among achieving permission to delivering massages and e-mails to the customers have arisen a new term in marketing which called "permission marketing". This phenomena of direct marketing provide this occasion for both customers in term of to be marketed volunteer beside for firms and companies, this fortune make the process of direct marketing easy to have better understanding about the individual interest and personal characteristic of their customers (Milne and Gordon 1993). Sterne\& Prior in year 2000, introduce the main key of permission marketing as unique way for understanding customers base on their interest and this 
help the firms in classifying them due to their interest and information they need and want (Sterne and Priore 2000).

\subsection{E-mail Marketing and Permission Issue}

By review relevant literature about permission marketing this issue is the followed subject to opt-in issue in E-mail marketing and its differences to spam E-mails (Sterne and Priore 2000; Raad, Yeassen et al. 2010). Spam massages named as massages which are not targeted, unwanted and consequently have negative insight among customers (Mehta and Sivadas 1995) Other research defines spam massaged to those massages which are not considering receivers wants and therefore these massages are inappropriate (Turban, King et al. 2004), also some believe that spam massages enter to the privacy of the people and this invasion of privacy will hurt the marketing body of firms there for many researches clarified that marketers should get the recipients ' permission before doing any marketing activity which uses email as a medium (Wright and Bolfing 2001; Rettie 2002; Raad, Yeassen et al. 2010).

Studies over E-mail marketing divided massages which delivered to customers into two different categories: Opt-in E-mails and spam E-mails. Opt-in E-mails are those electronic mails which obtain authorization prior of sending E-mails. As Sullivan and De Leeuw, 2003 stated; sending e-mails without getting the authorization make an unsocial E-mail(Sullivan and De Leeuw 2003). On the other hand spam massages unlike opt-in e-mails are sending to people's mailbox without permission and these kind of e-mails can be either welcome or not but Opt-in Emails are guarantee of acceptance of the massage which is delivered, so consequently it would be more effective in compare of spam type (Raad, Yeassen et al. 2010). One study noted spam massages as unethical way of E-mail marketing. On the other hand ISPs can ban promotional massages which people have not requested for them and consequently the whole marketing of that specific firm by that E-mail account will be ruined and this would hurt the business very bad, while by getting permission before sending delivering promotional E-mail not only firm priory got the acceptance of customer but also can be ensure that specific customers have already wanted and requested for that E-mail, so that E-mail would not be worthless (Sullivan and De Leeuw 2003).

\subsection{E-mail Marketing Success Factors}

Email marketing in term of cost effective tool and cheap instrument of doing marketing via internet is the main factor mentioned before in this study, on the other hand high number of responses in compare of other tools in internet marketing also argued by researchers. Short turnaround means send E-mail from firms and receive response from customers has been also mentioned by researcher(s). Advent of web pages, HTML, combination of video and audio together in web service and using them in marketing all are the scope of creativity and source of new idea in marketing aspect via internet that provided for the firms have created factors that push this medium as successful one (Rettie 2002).Email in year 2000 mentioned as new medium and customers reply to marketing activities is likely to be unfavorably affected by rising traffic volume (Rosenspan 2001).

Ruth Rettie in 2002 invested in UK to support some hypothesis and by analysis of his/her data collection which was among 30 campaign, supported following hypothesis base on findings that gives successful factors which are important in E-mail marketing:

- E-mail subject is very important to increase customer respond, more attractive subject brings more respond

- E-mails with more attractive incentive gets higher response

- Length of the email has inverse relation with customer response rate

- E-mails which contains image(s) in their entire get more response rate

\section{Web Marketing}

History of using web in commercial and use of digital technology to enhance and develop marketing attributes refers to 1994. There are so many evidences available that various organization attempt to recruit this phenomena to increase their core competency among other companies (Adam, Bednall et al. 2011). Another research mentioned, Since 1997 that internet commercialize in the world, marketers tend to use internet as medium which was cheaper and has greater capability in compare of other tools and platforms which they were using priory to distribute information and media in terms of global market. Argue about use of internet not only because of its ability but also because of some facilities that in managerial attributes in digital customers' data and electronic CRM provide this tool as a beneficial matter for marketers and marketing research (Fagerstrøm and Ghinea 2010). Ivie and McKay in 2011 discuss about role if information and declared: Information in this era has been become an important issue and for fulfilling this subject many website maintain multi faceted 
platform for people ,firms marketers and etc to use for their needs(Ivie, McKay et al. 2011) In view of web developer and those who work in integrating technology, internet marketing is about to built a strong web page and rescale with traffic that would occur by the visitors and customers of that specific company, firm, brand or etc (Frost and Strauss 2001), beside in advertisement and promotion aspect is impact of building brand and driving web traffic via advertisement massages(Breakenridge 2001).

\subsection{Banner Ads}

A banner is a graphic kind of advertisement that shows on the web pages. Due to the literatures banner ads are the most popular and commonly used for advertisement though their use in united state from $56 \%$ in 1998 to $19 \%$ in 2004.mostly banners are hyperlinked to an advertisement website. Scholars classified them into different type by considering their size of concerning, position and dynamic aspect e.g. animated rotated or static banners (Hamborg, Bruns et al. 2011). Banners effectiveness have been studied and described by different models previously (Rossiter and Bellman 1999; Vakratsas and Ambler 1999) and generally advertisement models for banners effectiveness shows below principals for advertisement subject:

- Advertiser provide and built structure and content of advertisement

- Consumers processes some or all the advertisement content

- Long lasting communication effect is the role of advertisement which contains mind-set of advertisement or communication effect of issues like brand awareness, buying facilitation and belief attitudes intention

Banner base on the literature has barely positive effect, Observations shows that when people are looking for something in webs even the large, colorful banners ignore by them. In literature this negative effect named as "banner blindness" that people ignore banners and are not motivated to follow banner in the web pages. On the other hand some other papers demonstrated positive effect of advertising banners and moreover mentioned that animated advertisement has better response and recall in compare of non animated banners; beside large banners have better click rate than small banners. Authors who have researched about this subject also clarified that fast moving banners are more likely to attract and consequently have better rate of clicking, as a result author perceived that task related selective of attention has very important role in banner advertisement field of study (Rossiter and Bellman 1999).

\subsection{Pop up Ads}

G. Susanne Bahr and Richard A. Ford stated that Pop up consumption is a standard operating procedure in HCI (Human Computer interaction) and used for non expert online users promoted to make a decision. These two authors also mentioned that most industries has engendered huge range of commercial products in Pop up format which can help customers to either block or allow these verity of pop up communication .Base on their research pop up size is not matter and pop up size can be removed from their artifacts (Bahr and Ford 2011).

Kim et al, 2009 and argued about pop up store, she said that a pop up store is temporary opportunity for brands and also designers to display their products in a limited time in a box which called as pop up store. She introduce that as efficient pattern for doing the marketing in web and even a special way to create demand for those product which has not been sold in the store (Kim, Fiore et al. 2010). Manchanda et al 2006 investigated on pop up promotion and her findings shows that pop up have some characteristic that can utilize to improve customer response over the internet (Manchanda, Dubé et al. 2006).

Anna Bergqvist in her thesis, 2006 researched on pop up stores and pop up retailer, she describe the advantages and opportunities of pop up retails base on literature and explained that pop up stores are unique feature as its provisional existence, In pop up store firms let the store gets open suddenly and vanish after awhile and during this time have to garb the online customers attention. According to her thesis pop ups can be both "mobile" and "event driven". Anna introduces it as capable way of guerrilla marketing technique. The major focus appear when a brand wants to present new product, that time pop up can be unique way of offering a product to give customers an opportunity to quickly get information about (Bergqvist and Leinoff 2011). According to Kim et al, (2009) pop up because of it temporality might fulfill of those customers who are looking for unique of experience since pop ups can offer an interactive environment that can connect customers to brand representatives or experts. Refer to Kim et al (2009) this is not the only advantages of this phenomenon in aspect of gathering data but also it a way to share their idea and perspectives. Pop up also give that ability which customers be a part of retail experience and branding process with the data and information which they may share with brand or retail representative of other customers (Kim, Fiore et al. 2010). 


\section{Social Network and Social Media Marketing}

Social media and doing marketing activities according to Berthon et al (2012), is an opportunities that comprises text, Images pictures, video and networks for both customers to customer and firm to customer. Base on that research text was the first social media that initially mentioned in blog. In addition, to illustrate some of these social networks and Micro-blogs, Twitter can be named as one of social networking site that make this option for user to read and write short massages that are limited to specific character to write or Flicker as a site which allow users to share their photo and their massaged in image format (Berthon, Pitt et al. 2012). Kaplan and Haenlein (2010), defines social media as "a group of internet-based application that build on the ideological and technological foundations of web 2.0, and that allow the creation and exchange of user-generated content"(Kaplan and Haenlein 2010).Another researcher mentions social media as a real power of make all connected (Hanna, Rohm et al. 2011).interaction between individuals and entities such as firms, organizations and companies gets easy and disseminated. Social media are very popular and very easy to access that push the ability of businesses to interact, reach and create relationship with large number of customers (Brogan 2010).These channel use internet service to change one to many dialogues to many to many dialogues that help the individual from being only a content user to content producer. In other word this can be consider as a tool which involves individuals to entire of the firms entity and become a part of it and by this relationship which is created by this fortune, firms and organization can enhance their quality, bring awareness about their promotion and also understand customers needs and want (Berthon, Pitt et al. 2012).

Weinberg (2009) expresses the process of targeting promotion of website, products or services on specific social media service as social media marketing. He believes that in compare of conventional marketing, social media marketing has more huge potential than conventional for customer reaching. Some literatures limited social media marketing just to marketing activities on SNSs but Weinberg is disagree with this issue and stated that social media marketing includes all services and tools like social software and defined that as: "Social media marketing is one of marketing approach that utilizes public social software platforms as a communication channel with the customer. Main Objective is to foster bidirectional communication" (Weinberg 2009).

Social media are some online application which aim is to facilitate interaction between users create collaboration and share content. Social media take in different type and forms like weblogs, wikis, podcasts, videos, pictures or etc. with considering the rapid speed of this media in the whole world not only existing social networks but also so many businesses, firms and companies try to reach to this phenomena and use it communication tools to enhance their profit and sustain it this competitive market. The nature of these websites is different from individual users, as business pint of view; managers try to do their business activities by using these media and recruit it in term of advertisement and marketing aspect to effect on its performance in customers mind. at the same time as commercial messages via this media is more effective and less cost for firm, with no doubt this phenomena could be very good place for firm to use to evaluate their business core (Kim and Ko 2011). According to Kim and Ko (2010), Social media can have spectacular impact on brand reputation. They added, one-third of research about this issue shows that posted opinion about product and brand in brand blog is seen much more and 36\% believes that brands which has blog are more positive in customers mind with those who have not (Kim, Kim et al. 2010).According to statistic that was in DEI worldwide (2008), $70 \%$ of customers use social media for getting information, $49 \%$ of above figure do their purchase decision base on information that they get from social media, $60 \%$ declared that they tend to get information from social media. That research also shows that $45 \%$ people who reach to information by social media site are involved to word of mouth. Moreover; this research declared that companies which do not use this option in their online marketing strategy are missing this fortune to achieve customers and reach to them to understand needs and want to fulfill that base on the information which is available on social media site (Kim and Ko 2011).

\section{Conclusion}

This research presented a conceptual underpinning of four different tools that firms may use in their marketing aspect to enhance their service and quality for their customers. Synthesis of relevant literature in aim of summarizing the key success factor of each parameter which presented in this paper is the target of this research. This review reveals advantages and issues related to each of the tools which were mobile marketing, e-mail marketing, web marketing and marketing through social network sites (SNS).By reviewing variety of relevant literatures, this research can conclude that there are many tools that firms can use to distribute their promotional massages and create awareness for their customers.

Mobile devices and marketing through mobile recently by introducing smart phone have changed and these enhancements in technologies especially in mobile devices brings so many advantages that most of the firms 
have used moreover issues like acceptance and adoption, role of trust in this phenomenon and customer satisfaction are mostly discussed in relevant literatures, also considering this issue that study about aesthetic, beauty and design in mobile content also level of research related to this issue is still inadequate and future studies will be valuable (Varnali and Toker 2010).

E-mail marketing according to literature is the most useful tool in internet and also the most cost effective phenomenon in electronic marketing for firm and businesses. Permission issue as a important factor in scholories declared that responses to those massages that already got admission from the receiver have better result in compare of those which will be considered as spam massages (Jackson and DeCormier 1999). E-mail marketing because of cheap instrument, being cost effective and majority of respondent is consider as a unique way of distributing promotional massages and creates value for firms' customers.

Marketing through web because of some capacities of nature of this phenomenon has become a essential need of firms. History of using this option goes back to 1994 base on the literatures (Adam, Bednall et al. 2011). Marketing through web in term of commercial and advertisement to bring traffic for the companies and firms was always a vital issue that web pages can fulfill the need of business owners. In this issue banner ads and pop ups play a very important role to catch attraction of online customer. Properties of banner ads and pop ups has been investigated in scholars and also the component of these two aspect in term of bringing information to the online customers has been studied before.

Weblogs, wikis, podcasts, videos, pictures or etc are some examples of social networks, combination of text, image video and etc all and all can help the firms to enhance their productivity and by using this capable option they can create value for their customers.

Social network sites also facilitate the relationship between firms and customers and by using this phenomenon companies can understand needs of their customers and also figure out the weakness and strength of their product in electronic world of mouth or customers comment and ideas (Berthon, Pitt et al. 2012).

According to literature many firms using so many tools to create relationship with customers moreover understanding which type and tool is more effective can be very important factors to help firms in enhancing their sale profitability and using which type in their marketing strategy. Future study of this research could be analyzing the preferences of people of specific region or country to have better understanding of perception of people of that specific area to utilize the electronic business according to their preference and taste.

\section{References}

Adam, S. et al. (2011). The web in marketing: information cue usage in two commercial domains, Promaco Conventions.

Ainin, S., \& Noor Ismawati, J. (2003). E-commerce stimuli and practices in Malaysia.

Bahr, G. S., \& Ford, R. A. (2011). How and why pop-ups don't work: Pop-up prompted eye movements, user affect and decision making. Computers in Human Behavior 27(2): 776-783. http://dx.doi.org/10.1016/j.chb.2010.10.030

Barnes, S. J., \& Scornavacca, E. (2004). Mobile marketing: the role of permission and acceptance. International Journal of Mobile Communications, 2(2), 128-139. http://dx.doi.org/10.1504/IJMC.2004.004663

Bauer, H. H. et al. (2005). Driving consumer acceptance of mobile marketing: a theoretical framework and empirical study. Journal of electronic commerce research, 6(3), 181-192.

Bergqvist, A., \& Leinoff, L. (2011). Once you pop your customer will shop-A study about pop-up stores.

Berthon, P. R. et al. (2012). Marketing meets Web 2.0, social media, and creative consumers: Implications for international marketing strategy. Business Horizons. http://dx.doi.org/10.1016/j.bushor.2012.01.007

Bigné, E. et al. (2007). Key drivers of mobile commerce adoption an exploratory study of Spanish mobile users. Journal of Theoretical and Applied Electronic Commerce Research, 2(2), 48-60.

Breakenridge, D. (2001). Cyberbranding: brand building in the digital economy. Upper Saddle River.

Brogan, C. (2010). Social media 101: Tactics and tips to develop your business online. Wiley. http://dx.doi.org/10.1002/9781118256138

Chowdhury, H. K. et al. (2006). Consumer attitude toward mobile advertising in an emerging market: An empirical study. International Journal of Mobile Marketing, 1(2), 33-42. 
Cyr, D. et al. (2006). Design aesthetics leading to m-loyalty in mobile commerce. Information \& Management, 43(8), 950-963. http://dx.doi.org/10.1016/j.im.2006.08.009

El-Gohary, H. (2010). E-Marketing-A literature Review from a Small Businesses perspective. International Journal of Business and Social Science, 1(1), 214-244.

Fagerstrøm, A., \& Ghinea, G. (2010). Web 2.0's marketing impact on low-involvement consumers. Journal of Interactive Advertising, 10(2), 67-71.

Frost, R., \& Strauss, J. (2001). Building effective web sites. Prentice Hall Professional Technical Reference.

Gressgard, L. J., \& Stensaker, I. (2006). The mobile service industry: strategic challenges and future business models. International Journal of Mobile Communications, 4(5), 509-531.

Haghirian, P., \& Inoue, A. (2007). An advanced model of consumer attitudes toward advertising on the mobile internet. International Journal of Mobile Communications, 5(1), 48-67. http://dx.doi.org/10.1504/IJMC.2007.011489

Hamborg, K. C. et al. (2011). The effect of banner animation on fixation behavior and recall performance in search tasks. Computers in Human Behavior.

Hanley, M. M. et al. (2006). Factors influencing mobile advertising acceptance: will incentives motivate college students to accept mobile advertisements. International Journal of Mobile Marketing, 1(1), 50-58.

Hanna, R., et al. (2011). We're all connected: The power of the social media ecosystem. Business Horizons. http://dx.doi.org/10.1016/j.bushor.2011.01.007

Harvey Tanakinjal, et al. (2010). Third screen communication and the adoption of mobile marketing: A Malaysia perspective. International Journal of Marketing Studies, 2(1), 36.

Ivie, T. et al. (2011). Marketing and Promotion of Library Services Using Web 2.0: An Annotated Mediagraphy. The Idaho Librarian: A Publication of the Idaho Library Association, 61(1).

Jackson, A., \& DeCormier, R. (1999). E-mail survey response rates: targeting increases response. Marketing Intelligence \& Planning, 17(3), 135-140. http://dx.doi.org/10.1108/02634509910271588

Kalyanam, K., \& McIntyre, S. (2002). The e-marketing mix: a contribution of the e-tailing wars. Journal of the Academy of Marketing Science, 30(4), 487-499. http://dx.doi.org/10.1177/009207002236924

Kaplan, A. M., \& Haenlein, M. (2010). Users of the world, unite! The challenges and opportunities of Social Media. Business Horizons, 53(1), 59-68. http://dx.doi.org/10.1016/j.bushor.2009.09.003

Karjaluoto, H., et al. (2008). Exploring Gender Influence on Customer's Intention to Engage Permission-based Mobile Marketing. Electronic markets, 18(3), 242-259. http://dx.doi.org/10.1080/10196780802265793

Kiang, M. Y. et al. (2000). Marketing on the Internet- who can benefit from an online marketing approach? Decision Support Systems, 27(4), 383-393. http://dx.doi.org/10.1016/S0167-9236(99)00062-7

Kim, A. J. \& Ko, E. (2011). Do social media marketing activities enhance customer equity? An empirical study of luxury fashion brand. Journal of Business Research. http://dx.doi.org/10.1016/j.jbusres.2011.10.014

Kim, H. et al. (2010). Psychographic characteristics affecting behavioral intentions towards pop-up retail. International Journal of Retail \& Distribution Management, 38(2), 133-154. http://dx.doi.org/10.1108/09590551011020138

Kim, H. W. et al. (2007). Value-based adoption of mobile internet: an empirical investigation. Decision Support Systems, 43(1), 111-126. http://dx.doi.org/10.1016/j.dss.2005.05.009

Kim, J. et al. (2010). The customer-salesperson relationship and sales effectiveness in luxury fashion stores: The role of self monitoring. Journal of Global Fashion Marketing, 1(4), 230-239.

Kim, Y., \& Zhang, P. (2010). Continued Use of Technology: Combining Controlled and Automatic Processes. Citeseer.

Manchanda, P. et al. (2006). The effect of banner advertising on internet purchasing. Journal of Marketing Research, 98-108. http://dx.doi.org/10.1509/jmkr.43.1.98

Mehta, R., \& Sivadas, E. (1995). Direct marketing on the Internet: An empirical assessment of consumer attitudes. Journal of Direct Marketing, 9(3), 21-32. http://dx.doi.org/10.1002/dir.4000090305

Milne, G. R., \& Gordon, M. E. (1993). Direct mail privacy-efficiency trade-offs within an implied social contract framework. Journal of Public Policy \& Marketing, 206-215. 
Okazaki, S. (2004). How do Japanese consumers perceive wireless ads? A multivariate analysis. International Journal, 23(4), 429-454.

Peppers, D., \& Rogers, M. (2000). Email marketing maximized. Peppers and Rodgers Group, Stamford, CA.

Persaud, A., \& Azhar, I. (2012). Innovative Mobile Marketing via Smartphones: Are Consumers Ready? Marketing Intelligence \& Planning, 30(4), 3-3.

Raad, M. et al. (2010). Impact of spam advertisement through email: A study to assess the influence of the anti-spam on the email marketing. Afr. J. Bus. Manage, 4(11), 2362-2367.

Rettie, R. (2002). Email marketing: success factors.

Rosenspan, A. (2001). Opinion Piece: Permission is not enough. Journal of Direct, Data and Digital Marketing Practice, 2(3), 215-218. http://dx.doi.org/10.1057/palgrave.im.4340091

Rossiter, J. R., \& Bellman, S. (1999). A proposed model for explaining and measuring web ad effectiveness. Journal of Current Issues and Research in Advertising, 21, 13-32. http://dx.doi.org/10.1080/10641734.1999.10505086

Salehi, M. et al. Dissimilarity of E-marketing VS traditional marketing.

Shankar, V., \& Balasubramanian, S. (2009). Mobile marketing: A synthesis and prognosis. Journal of Interactive Marketing, 23(2), 118-129. http://dx.doi.org/10.1016/j.intmar.2009.02.002

Sheth, J. N., \& Sharma, A. (2005). International e-marketing: opportunities and issues. International Marketing Review, 22(6), 611-622. http://dx.doi.org/10.1108/02651330510630249

Sterne, J., \& Priore, A. (2000). Email marketing: using email to reach your target audience and build customer relationships, Wiley.

Sullivan, J. D., \& De Leeuw, M. B. (2003). Spam after Can-Spam: How Inconsistent Thinking Has Made a Hash out of Unsolicted Commercial E-Mail Policy. Santa Clara Computer \& High Tech. LJ 20: 887.

Sultan, F., \& Rohm, A. J. (2008). How to Market to Generation M (obile). MIT Sloan management review, 49(4), 35-41.

Suoranta, M., \& Mattila, M. (2004). Mobile banking and consumer behaviour: New insights into the diffusion $\begin{array}{lllll}\text { pattern. Journal of Financial Services } & \text { Marketing, }\end{array}$ http://dx.doi.org/10.1057/palgrave.fsm.4770132

Vakratsas, D., \& Ambler, T. (1999). How advertising works: what do we really know? The Journal of Marketing, 26-43. http://dx.doi.org/10.2307/1251999

Varadarajan, P. R., \& Yadav, M. S. (2002). Marketing strategy and the internet: an organizing framework. Journal of the Academy of Marketing Science, 30(4), 296-312. http://dx.doi.org/10.1177/009207002236907

Varnali, K., \& A. Toker (2010). Mobile marketing research: The-state-of-the-art. International Journal of Information Management, 30(2), 144-151. http://dx.doi.org/10.1016/j.ijinfomgt.2009.08.009

Weinberg, T. (2009). The new community rules: Marketing on the social web, O'Reilly Media.

Wreden, N. (1999). Mapping the Frontiers on Email Marketing. Harvard Management Communication Letter 9.

Wright, N. D., \& Bolfing, C. P. (2001). Marketing via Email: Maximizing its Effectiveness Without Resorting to Spam.

Zhang, J., \& Mao, E. (2008). Understanding the acceptance of mobile SMS advertising among young Chinese consumers. Psychology and Marketing, 25(8), 787-805. http://dx.doi.org/10.1002/mar.20239 